\section{Local spreading of MSL complexes from roX genes on the Drosophila X chromosome}

\author{
Hyangyee Oh, ${ }^{1}$ Yongkyu Park, ${ }^{2}$ and \\ Mitzi I. Kuroda ${ }^{1,2,3,4}$
}

\begin{abstract}
${ }^{1}$ Interdepartmental Program in Cell and Molecular Biology, ${ }^{2}$ Howard Hughes Medical Institute, ${ }^{3}$ Department of Molecular and Cellular Biology, Baylor College of Medicine,

Houston, Texas 77030, USA
\end{abstract}

MSL proteins and noncoding roX RNAs form complexes to up-regulate hundreds of genes on the Drosophila male $\mathrm{X}$ chromosome, and make $\mathrm{X}$-linked gene expression equal in males and females. Altering the ratio of MSL proteins to roX RNA dramatically changes $\mathrm{X}$-chromosome morphology. In protein excess, the MSL complex concentrates near sites of $r o X$ transcription and is depleted elsewhere. These results support a model for distribution of MSL complexes, in which local spreading in cis from roX genes is balanced with diffusion of soluble complexes in trans. When overexpressed, MSL proteins can recognize the $X$ chromosome, modify histones, and partially restore male viability even in the absence of roX RNAs. Thus, the protein components can carry out all essential functions of dosage compensation, but roX RNAs facilitate the correct targeting of MSL complexes, in part by nucleation of spreading from their sites of synthesis.

Supplemental material is available at http://www.genesdev.org.

Received February 7, 2003; revised version accepted April 4, 2003.

The establishment and maintenance of chromatin organization by histone modification and chromatin-remodeling complexes has been postulated to occur in some cases by initial recognition of a nucleation site, followed by spreading in cis into flanking sequences (Lee and Jaenisch 1997; Bannister et al. 2001; Lachner et al. 2001; Nakayama et al. 2001; Ho et al. 2002). In dosage compensation of the Drosophila male X chromosome, MSL (male-specific lethal) proteins and $\operatorname{roX}(\underline{\mathrm{RNA}} \underline{\text { on }} \underline{\mathrm{X}})$ RNAs form large complexes that modify histone tails and can spread long distances from initiation sites into flanking chromatin (Kelley et al. 1999; Meller et al. 2000; Park et al. 2002). The two known roX genes are located on the $X$ chromosome (Amrein and Axel 1997; Meller et al. 1997) and are thought to have dual functions. First, roX RNAs are components of the MSL complex (Meller et al. 2000;

[Keywords: Drosophila dosage compensation; noncoding roX RNAs; MSL proteins]

${ }^{4}$ Corresponding author.

E-MAIL mkuroda@bcm.tmc.edu; FAX (713) 798-3432.

Article and publication are at http://www.genesdev.org/cgi/doi/10.1101/ gad.1082003.
Smith et al. 2000). The MSL proteins are unable to bind the $\mathrm{X}$ chromosome efficiently without roX RNA, resulting in male lethality (Franke and Baker 1999; Meller and Rattner 2002). Second, roX transgenes can function as nucleation sites for ectopic targeting and spreading of MSL complexes into flanking autosomes regardless of location (Kelley et al. 1999). We have inferred that similar spreading around the endogenous roX genes could contribute to targeting the MSL complex to the correct chromosome.

Ectopic spreading of MSL complexes on autosomes is profoundly influenced by the number of roX genes in the nucleus (Park et al. 2002). When both endogenous roX genes are deleted so that a single roX autosomal transgene is the sole source of roX RNA, consistent spreading of the MSL complex occurs for long distances (several megabase pairs) into flanking chromatin. However, when several roX genes compete for a limiting amount of MSL proteins, ectopic spreading from autosomal roX transgenes is very rare, and instead all MSL complexes diffuse to the X chromosome. A model based on these observations proposes that there are two pools of MSL complexes. If MSL proteins are abundant and rapidly assemble onto growing roX transcripts, functional complexes will be completed before release of the nascent roX transcript from the DNA template. These complexes are postulated to immediately bind the flanking chromosome regardless of sequence and begin spreading in cis (Fig. 1A). When multiple roX genes are present, they compete for a finite supply of MSL proteins, thus slowing the assembly of complete complexes. Under these conditions, nascent roX RNA will be released from the template with an incomplete set of MSL subunits. After maturation is completed in solution, these complexes are postulated to diffuse through the nucleus until encountering the $\mathrm{X}$ chromosome (Fig. 1B). How such soluble MSL complexes recognize and bind the $\mathrm{X}$ chromosome is not understood. We initially postulated that, besides the two roX genes, there were $\sim 35$ additional "chromatin entry sites" that would also initiate MSL spreading (Kelley et al. 1999). However, the nature of these sites remains a mystery.

To date, all evidence for cis spreading comes from autosomal roX transgenes. Here, we demonstrate that MSL complexes do spread locally from the endogenous roX genes on the $\mathrm{X}$ chromosome, the natural target of dosage compensation. We find that wild-type males require a balance of MSL proteins and roX RNAs to evenly distribute MSL complexes both locally and at a distance along the X chromosome. When we artificially increase the amounts of MSL1 and MSL2, thought to be the limiting proteins (Kelley et al. 1997; Chang and Kuroda 1998; Park et al. 2002), MSL complexes spread predominantly over a local segment of the X chromosome surrounding a roX gene. More remote regions bind little MSL complex. This dramatically alters the morphology of polytene X chromosomes. Surprisingly, we found that overexpressing MSL1 and MSL2 partially restored viability to males lacking roX RNA. This indicates that the MSL proteins have intrinsic affinity for the X chromosome that is enhanced or stabilized in wild-type males by the roX RNAs. 


\section{A High ratio of MSL proteins / roXRNA (cis > trans)}
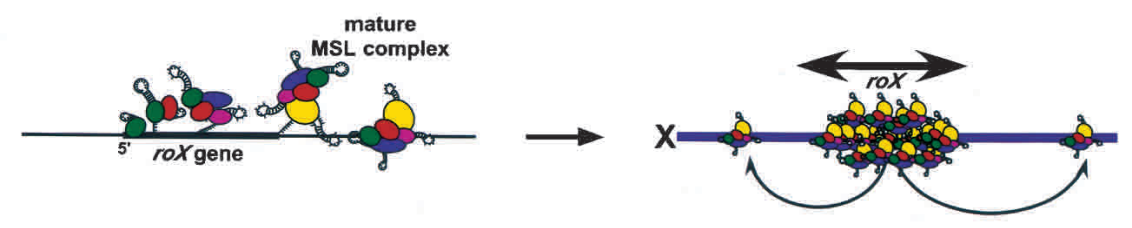

B Normal ratio of MSL proteins / roXRNA

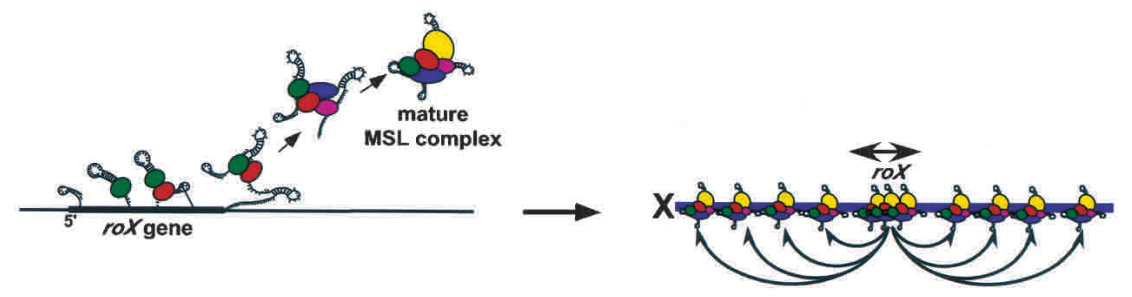

Figure 1. Model for cis-versus-trans interaction of MSL complexes with the X chromosome. (A) If the local concentration of MSL proteins is high at the site of roX transcription, a complete set of MSL proteins will be assembled efficiently on the nascent roX RNA, leading to local MSL spreading in cis. If the rate of MSL protein assembly is accelerated by overexpressing MSL1 and MSL2, extensive cis spreading of MSL complexes will predominate and trans interactions will decrease. $(B)$ Conversely, if the local concentration of MSL proteins is low, only partial MSL complexes will be assembled on the nascent roX RNA prior to release from the DNA template. Released complexes can finish assembly in the nucleoplasm, but are unlikely to return to the site of roX synthesis. In normal conditions, the rate of roX RNA transcription and the rate of MSL protein assembly on nascent roX RNA are optimized, resulting in balanced cis and trans interactions of MSL complexes with the X chromosome.

\section{Results and Discussion}

Spreading of MSL complexes from roX genes on the $X$ chromosome

There are two known roX genes located on the $\mathrm{X}$ chromosome; roX1 at 3F near the telomere and roX2 at $10 \mathrm{C}$ in the middle of the chromosome (Fig. 2A). The even distribution of MSL complexes in a banded, reproducible pattern in single roX mutants, with no preference for the regions surrounding $3 \mathrm{~F}$ or $10 \mathrm{C}$, does not suggest regional spreading (Meller et al. 1997; Kelley et al. 1999; Meller and Rattner 2002). Our recent finding, that the ratio of MSL proteins to roX RNAs affects whether or not MSL complexes spread in cis near autosomal roX transgenes (Park et al. 2002), prompted us to ask if increasing the levels of MSL proteins would alter balanced targeting of the $\mathrm{X}$ chromosome. We used the previously characterized Hsp83 promoter-driven transgenes, [H83M1] (previously known as M1-ECTOPIC) and [H83M2] (Chang and Kuroda 1998) to overexpress the msl1 and msl2 genes in roX $1^{-}$or roX $2^{-}$single mutants. Under these conditions, we found that the roX genotype greatly affected X-chromosome morphology. In roX $1^{-}$larvae, MSL localization to the $\mathrm{X}$ chromosome was concentrated over the middle region of the $\mathrm{X}$ chromosome surrounding the roX $2^{+}$gene (Fig. 2B). In contrast, in roX2- larvae, MSL localization was extensive around the tip of the $\mathrm{X}$ chromosome around the roX $1^{+}$gene (Fig. 2C). More distant regions of the X chromosome were deficient for MSL complexes. The MSL-faint regions of the X chromosome displayed a collapsed, narrow morphology reminiscent of that seen in mle or roX1- roX2 $2^{-}$mutants (Belote and Lucchesi 1980; Meller and Rattner 2002). MSL-bright regions surrounding either $\mathrm{roX}^{+}$gene showed very diffuse DAPI staining, reminiscent of chromosome puffing. Although chromosome morphology varied from nucleus to nucleus within the same individual, $\sim 20 \%-30 \%$ of the nuclei showed local alteration of morphology around roX genes. These results strongly suggest that spreading really occurs from the roX1 and roX2 genes in their native locations, and can be exaggerated by overexpression of MSL proteins. The width of polytene chromosomes is often correlated with transcriptional activity (Offermann 1936; Dobzhansky 1957). The gross alteration in X-chromosome morphology seen in these males suggests that affected regions might be overexpressed and depleted regions underexpressed. This could lead to reduced male viability (Table 1).

To determine whether increased spreading would be evident when both roX genes were functional, we overexpressed MSL1 and MSL2 in otherwise wild-type males. These males displayed short, wide X chromosomes that stained strongly with MSL antibodies but showed faint, diffuse staining with DAPI (Fig. 2D). This morphology suggests overall enhanced MSL binding and function on the X chromosome that could be caused by extensive spreading from both roX loci. This is somewhat similar to the phenotype of iswi or nurf301 mutants (Deuring et al. 2000; Badenhorst et al. 2002), raising the strong possibility that it reflects aberrant chromatin organization. Although male viability was decreased by overexpression of MSL1 and MSL2 (Table 1), both male and female flies can tolerate surprisingly large perturbations in MSL localization patterns on the X chromosome (Kelley et al. 1997, 1999).

To test our assumption that the roX genes are the precise sites of initiation of MSL spreading, we moved the roX $1^{+}$or $\mathrm{roX}^{+}$genes to new locations along the $\mathrm{roX}^{-} \mathrm{X}$ chromosome. In each of 10 sites tested, additional MSL1 and MSL2 protein produced bright MSL staining and diffuse chromosome morphology surrounding the relocated roX ${ }^{+}$gene (Fig. 2E,F; data not shown). Again, more distant regions of the $\mathrm{X}$ chromosome had much less MSL staining. Because a strong bias for local MSL spreading was seen at each segment of the X chromosome tested, the sequences surrounding the endogenous roX genes are unlikely to contain special spreading elements. Moreover, some roX transgenes displayed a strong preference for regional spreading from their site of insertion with only wild-type levels of MSL1 and MSL2 (Fig. 2G). This indicates that our conditions of MSL1 and MSL2 overexpression were not extreme, and that changes in the MSL protein:roX RNA ratio or chromatin environment can produce large shifts in the pattern of local MSL spreading.

To determine whether overexpression of MSL1 and MSL2 affected the steady-state levels of roX RNAs, we performed Northern analysis (Fig. $2 \mathrm{H}$ ). Compared with normal males (Fig. 2H, lanes 1,3,5), the levels of roX RNAs were increased when MSL1 and MSL2 were over- 

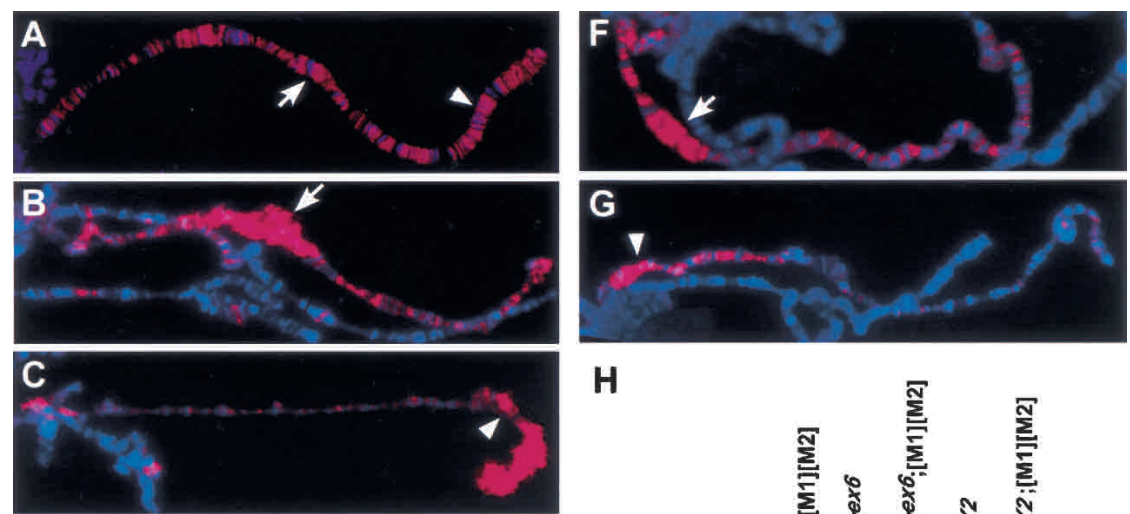

H
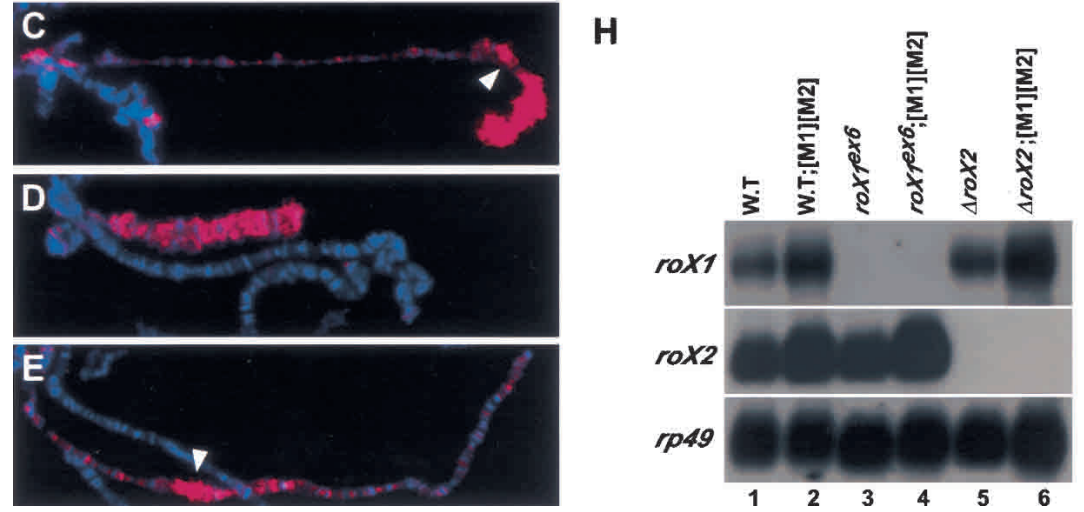

Figure 2. $(A-G)$ Local cis spreading of MSL complexes on the X chromosome. Male polytene chromosomes were stained with anti-MSL1 antibodies and visualized with Texas Red-conjugated secondary antibody (red). DNA was stained with DAPI (blue). Arrowheads and arrows indicate the locations of the roX1 and roX2 genes, respectively. The genotypes are wild type $(A), \operatorname{roX} 1^{\operatorname{ex6}} ;[\mathrm{M} 1][\mathrm{M} 2](B), D f(1) \operatorname{roX}^{52} ;[\mathrm{M} 1][\mathrm{M} 2](C)$, wild type; $[\mathrm{M} 1][\mathrm{M} 2](D), \operatorname{roX} 1^{\operatorname{ex6}}$ $D f(1) \operatorname{roX} 2^{52}\left[w^{+}\right.$GMroX1-13A]; [M1][M2] $(E)$, roX1ex6 Df(1)roX2 ${ }^{52}\left[w^{+}\right.$GMroX2-14F]; [M1][M2] $(F)$, roX1 ${ }^{\text {ex }}$ Df(1)roX2 ${ }^{52}\left[w^{+}\right.$GMroX1-18C] without extra MSL1 and MSL2 (G). [M1][M2] stands for $\left[w^{+}\right.$H83M1] $\left[w^{+}\right.$H83M2] $/+$on the third chromosome. Full genotypes of crosses are listed in Materials and Methods. $(H)$ Northern blot showing that the steady-state level of roX RNA is increased with overexpression of MSL1 and MSL2. The same membrane was hybridized to an rp49 probe as a loading control

expressed (Fig. 2H, lanes 2,4,6). Under these conditions, the local assembly of MSL complexes might be amplified through a positive feedback loop. For example, the transcription of roX genes might be increased by the high concentration of MSL complexes, or the accelerated rate of MSL protein assembly with nascent roX RNA could lead to increased stabilization of the RNA that might otherwise be degraded. Thus, the higher density of MSL complexes around the roX genes (Fig. 2B-G) probably results from two factors. There is an overall increase in MSL complexes, and complexes normally destined for remote parts of the $\mathrm{X}$ chromosome instead remain local. This shows that the wild-type male $\mathrm{X}$ chromosome is not saturated with MSL complex, but rather that the distribution must be under active control.

\section{Overexpressed MSL1 and MSL2 can partially overcome a lack of roX RNAs}

Males lacking both roX1 and roX2 have only small amounts of MSL proteins bound to a subset of sites on the X chromosome (Meller and Rattner 2002). Depending on poorly understood differences in genetic background, $\sim 95 \%-99.9 \%$ of such males die before adulthood. Surprisingly, a small number of adult males somehow survive without any detectable roX RNA (Meller and Rattner 2002; Stuckenholz 2002). Larval polytene chromosomes from such animals display very poor morphology, with ectopic MSL binding to the chromocenter and some autosomal sites (Fig. 3A; Meller and Rattner 2002). For comparison, mutants for each of the five known msl genes show a complete male lethal phenotype with no escapers. Because wild-type and single roX mutant males each had altered X-chromosome morphology when MSL1 and MSL2 were overexpressed, we asked whether roX1- roX2 double-mutant X chromosomes would also be affected by these conditions. We found that overexpression of MSL1 and MSL2 improved the morphology of all polytene chromosomes in roX $X^{-}$males. In addition, the $\mathrm{X}$ chromosome displayed much more robust binding of MSL1 (Fig. 3B) and MSL2 (data not shown) than brothers with only wild-type levels of MSL proteins (Fig. 3A). This indicates that the MSL proteins have an intrinsic ability to recognize the $\mathrm{X}$ chromosome. At normal MSL levels, this binding is weak but greatly enhanced by roX RNA. When MSL proteins are artificially overproduced, however, MSL binding to the $\mathrm{X}$ chromosome is at least partially RNA-independent.

Given their greatly improved X-chromosome morphology and MSL localization, we examined roX $1^{-}$ roX2- ; $\left.{ }^{-} 83 \mathrm{M} 1\right][\mathrm{H} 83 \mathrm{M} 2] /+$ males for viability (Table 1). We crossed roX mutant females from three genetically different backgrounds to male flies overexpressing MSL1 and MSL2. Progeny from all three lines showed enhanced male viability (up to 90-fold improvement) with overexpression of MSL1 and MSL2. This suggests that the protein components of the MSL complex mediate the chromatin changes during dosage compensation. Normally the roX RNAs play a crucial role in assembly or targeting of complexes, which can be partially recapitulated by MSL overexpression.

Screening for additional noncoding RNA component(s) of MSL complexes

One qualification of our results is that the roX $1^{-}$roX2 double-mutant stocks might not be truly null for all roX RNAs. Although the roX2 allele is a full deletion, the roX $1^{\text {ex } 6}$ allele removes only the $5^{\prime}$ half of the gene, but retains the last $\sim 2.3 \mathrm{~kb}$ of the locus (Kelley et al. 1999). If a truncated roX1 transcript were incorporated into MSL complexes, we would expect it to accumulate to detectable levels. However, using Northern analysis (Fig. 4A) or reverse transcriptase PCR (RT-PCR; Fig. 4B), we were unable to detect any roX1 RNA in ro $X^{-}$escaper males carrying the roX $1^{e x 6}$ allele. Coupled with the observation that the roX $1^{e x 6}$ allele showed no evidence of MSL attraction and spreading in our polytene chromosome assay (Fig. 2B,E-G), these results suggest that the roX $1^{\text {ex } 6}$ allele is nonfunctional.

We next asked whether additional species of roX RNA from unidentified genes might have gone undetected. We 
Table 1. Effect of overexpression of MSL proteins on male viability of roX mutants

\begin{tabular}{|c|c|c|c|c|c|}
\hline \multicolumn{6}{|c|}{$\%$ viability of progeny overexpressing MSL1 and MSL2 } \\
\hline $\begin{array}{l}\text { Cross } \\
\text {. }\end{array}$ & roX genotype ${ }^{\mathrm{a}}$ & Female & Female; $[\mathrm{M} 1][\mathrm{M} 2] /+$ & Male & Male; $[\mathrm{M} 1][\mathrm{M} 2] /+$ \\
\hline 1 & WT & $100^{\mathrm{b}}(1181)^{\mathrm{c}}$ & $0.9(10)$ & $56.5(667)$ & $31.3(370)$ \\
\hline 2 & $\operatorname{roX} 1^{-}$ & $100(1364)$ & $0.4(6)$ & $63.4(865)$ & $34.2(466)$ \\
\hline 3 & $\operatorname{roX} 2^{-}$ & $100(646)$ & $0.5(3)$ & $86.5(559)$ & $75.5(488)$ \\
\hline 4 & roX $1^{-}$roX $2^{-}$ & $100(1286)$ & $11.1(143)^{\mathrm{d}}$ & $0.1(1)$ & $7.2(93)$ \\
\hline 5 & roX $1^{-}$roX2- & $100(1185)$ & $9.3(110)^{\mathrm{d}}$ & $0.9(11)$ & $25.4(301)$ \\
\hline 6 & $\operatorname{roX} 1^{-} \operatorname{roX} 2^{-}$ & $100(2239)$ & $16.0(358)^{\mathrm{d}}$ & $6.6(147)$ & 44.3 (992) \\
\hline
\end{tabular}

Full genotypes of crosses:

1. y $\mathrm{W} \times \mathrm{W} / \mathrm{Y} ; \mathrm{ms} 12 \mathrm{cn} ;[\mathrm{M} 1][\mathrm{M} 2\} /+$

2. y $w \operatorname{rox} 1^{\text {ext }} \times w / Y ; m s 12 \mathrm{cn} ;[\mathrm{M} 1][\mathrm{M} 2] /+$

3. $w D f(1) r o X 2^{52} ;\left[w^{+} 4 \Delta 4.3\right] \times w / Y ; m s 12 \mathrm{cn} ;[\mathrm{M} 1][\mathrm{M} 2] /+$

4. y $w \operatorname{rox} 1^{e x 6} D f(1) r o X 2^{52}\left[w^{+} 4 \Delta 4.3\right] \times w / Y$; msl2 cn; [M1][M2]/+

5. y $w$ rox $1^{\text {ex6 }} D f(1) r o X 2^{52} ;\left[w^{+} 4 \Delta 4.3\right] \times w / Y$; msl2 cn; [M1][M2]/+

6. $\operatorname{rox}^{\text {ex6 }} \mathrm{Df}(1) \mathrm{roX}^{52} ;\left[\mathrm{w}^{+} 4 \Delta 4.3\right] \times \mathrm{w} / \mathrm{Y} ; \mathrm{ms} 12 \mathrm{cn} /+$; [M1][M2]/TM3 Sb

The number of XO males and XXY females is not included.

${ }^{a}$ This indicates the male $\mathrm{X}$ genotype; females are heterozygous, as they also carry one wild-type X chromosome.

${ }^{b}$ Numbers represent the percent of expected when compared with control females that do not overexpress MSL1 and MSL2.

${ }^{\mathrm{c}}$ Numbers in parentheses show actual number of progeny.

${ }^{\mathrm{d} C}$ Compared with the survival of wild-type females overexpressing MSL1 and MSL2, these females show enhanced viability, possibly because they have one wild-type and one roX mutant $\mathrm{X}$ chromosome.

immunoprecipitated MSL complexes from wild-type embryos, recovered RNA, prepared cDNA, performed subtractive hybridization using excess female cDNA to deplete nonspecific contaminants, and cloned the enriched products. Out of 15 randomly picked colonies, we found that the resulting small cDNA library contained $\sim 70 \%$ roX1 and roX2 subclones (Supplementary Table 1A). To increase the chance of discovering new roX RNA(s), colonies containing roX 1 or roX 2 were excluded by colony hybridization with roX 1 and roX 2 probes. Another 31 clones were sequenced, but all represented nonspecific abundant RNAs (Supplementary Table 1B). Thus, we found no candidates for additional roX species. We conclude that if the MSL complex contains other RNA species, they have very different characteristics from roX1 and roX2. The fact that the MSLs spread from only the roX2 $2^{+}$locus in a roX $1^{-}$mutant (Fig. 2B), or the roX $1^{+}$locus in a roX2 $2^{-}$background (Fig. 2C), also strongly suggests that there are no additional RNAs functioning like roX1 and roX2.

\section{Colocalization of MSL proteins to the X chromosome without roX $R N A$}

We further investigated how loss of roX RNA affected MSL complexes in males overexpressing MSL1 and MSL2. Polytene chromosomes were stained with antibodies to each of the five MSL proteins and histone $\mathrm{H} 4$ acetylated at Lys 16 . We found that MSL1, MSL2, MSL3, MOF, and H4Ac16 were colocalized to the X chromosome under these conditions (Fig. 3B-D; data not shown), showing substantial rescue of MSL localization to the $\mathrm{X}$ chromosome in the roX $X^{-}$mutant. The restoration of the precise MSL pattern was incomplete, as MSL proteins were still present at an increased number of autosomal sites and the heterochromatic chromocenter, as is seen in roX $X^{-}$mutants with wild-type levels of MSL proteins (Fig. 3A). Surprisingly, localization of the MLE helicase differed significantly from the other MSL pro- teins. Although MLE binds the X chromosome robustly in wild-type nuclei (Fig. 3E), it shows only very faint staining on the $\mathrm{X}$ chromosome in the absence of roX RNAs. However, it is still colocalized to some autosomal sites and the chromocenter with the other MSL proteins (Fig. 3F-H). These results demonstrate that stable localization of MLE to the male X chromosome is strongly dependent on roX RNAs, and is consistent with previous results showing that association of MLE with the X chromosome is particularly RNase-sensitive (Richter et al. 1996). Earlier work demonstrated the reciprocal result: roX RNA cannot bind the $\mathrm{X}$ chromosome without MLE helicase (Meller et al. 2000). We do not understand what attracts MLE to the ectopic autosomal sites and chromocenter, but note that MLE has an RNase-sensitive affinity for all chromosomes when overexpressed (Richter et al. 1996).

Given that males cannot live without mle function, why do some of these males survive without MLE enrichment on the $\mathrm{X}$ chromosome? We tested the possibility that the mle requirement also could be overcome by overexpression of MSL1 and MSL2. However, we recovered no mle escaper males in crosses in which excess MSL1 and MSL2 were supplied (data not shown). Therefore, although MLE is no longer concentrated on the X chromosome in roX mutant males, it still performs an essential function in dosage compensation. Perhaps it acts catalytically, associating only transiently with the other MSL proteins (Copps et al. 1998), or is sufficient when present at substoichiometric levels relative to the other MSL subunits.

If roX RNAs are not absolutely essential for MSL targeting, could they play some other role? One possibility is that assembly with the RNAs might stabilize the MSL proteins. To test this possibility, we checked the level of each MSL protein in roX $X^{-}$adult male escapers by Western blot (Fig. 4C). The amount of each MSL protein in these males was similar to that of wild-type males. This does not exclude a transient role for roX RNAs in MSL 
Oh et al.

protein integrity but suggests that they instead play a specific role in efficient assembly or X localization of the MSL complex.

\section{Model for MSL targeting to the X chromosome}

Earlier observations that the MSL complex could spread in cis from an autosomal roX transgene lead to speculation that complexes normally spread from the endogenous roX loci on the $\mathrm{X}$ chromosome to paint the entire chromosome (Kelley et al. 1999). However, the initial characterization of roX1 clearly demonstrated that soluble MSL complexes could diffuse between chromosomes (Meller et al. 1997; Kelley et al. 1999). More recent work revealed that the ability of the MSL complex to spread from a site of $r o X$ transcription, or diffuse away, is highly sensitive to the balance between MSL proteins and roX transcripts in the nucleus (Park et al. 2002). Here, we demonstrate that the wild-type pattern of MSL complexes along the male $\mathrm{X}$ chromosome is the result of a delicate interplay between two targeting strategies. Lo-
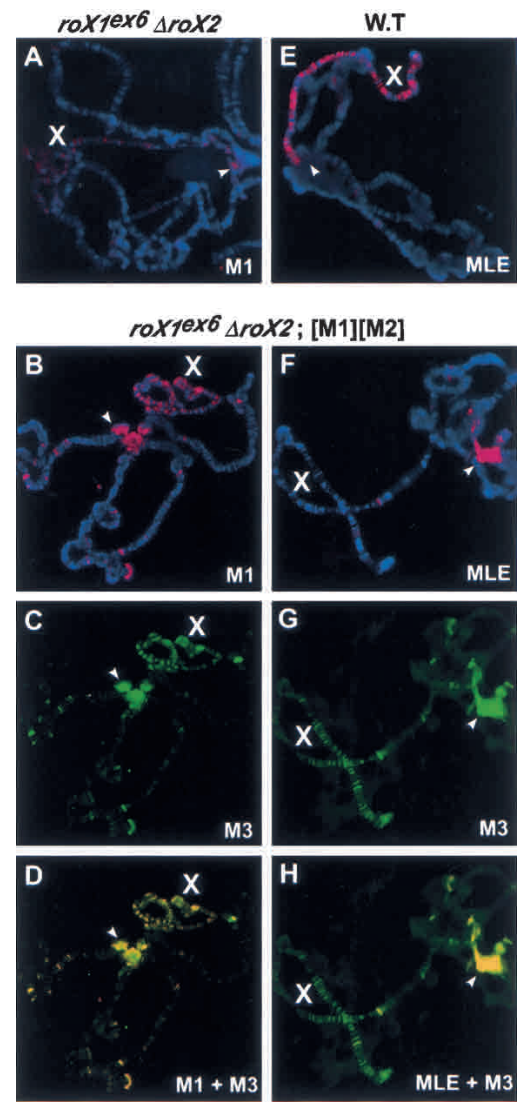

Figure 3. Colocalization of MSL proteins to the $\mathrm{X}$ chromosome without roX RNA. Male polytene chromosomes were immunostained and visualized by FITC-conjugated secondary antibodies for anti-MSL3 (green) or Texas Red-conjugated secondary antibodies for anti-MSL1 or anti-MLE (red). DNA was stained with DAPI (blue). Arrowheads indicate the heterochromatic chromocenter, which shows robust MSL binding in roX- mutants. The genotypes of male larvae are roX1 ex6 $D f(1) r o X 2^{52} ;\left[w^{+} 4 \Delta 4.3\right](A), y$ w roX1 $1^{\text {ex6 }}$ $D f(1) \mathrm{roX2}^{52}\left[\mathrm{w}^{+} 4 \Delta 4.3\right] ; \mathrm{msl2} \mathrm{cn} /+$; [M1][M2]/+ $(B-D, F-H)$, and $y \mathrm{w}$ (wild type; $E$ ). ro $X^{-}$mutants with different genetic backgrounds and escaper frequencies showed similar chromosomal staining (data not shown).

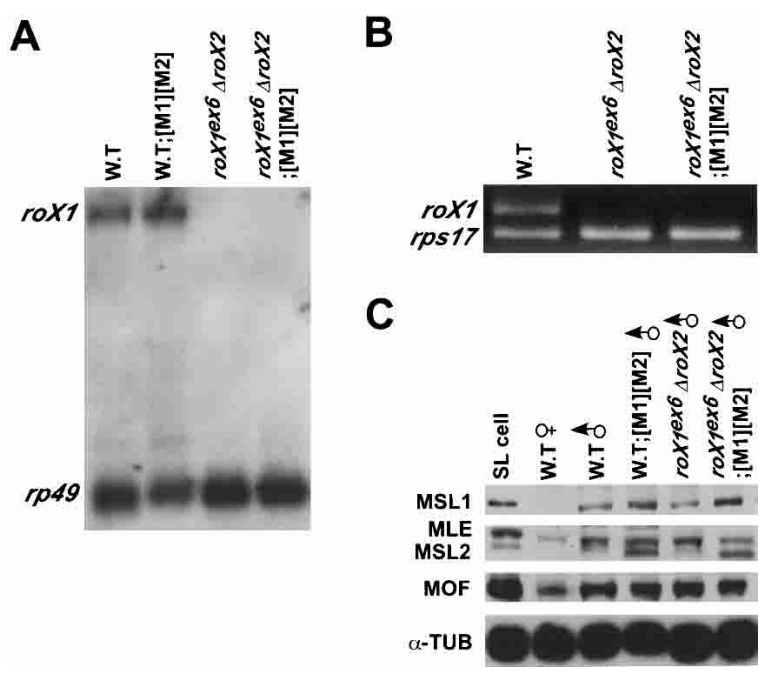

Figure 4. MSL proteins are partially functional without roX RNA. To determine whether an incompletely deleted roX1 RNA retains residual expression, Northern blotting $(A)$ and RT-PCR $(B)$ were performed. (A) A full-length roX1 genomic fragment was used as a probe to detect any aberrant RNA from the roX $1^{\text {ex }}$ gene in males. The full genotype of the roX mutant is roX $1^{\text {ex6 }} \mathrm{Df}(1) \mathrm{roX} 2^{52} ;\left[\mathrm{W}^{+}\right.$ $4 \Delta 4.3$ ], which showed the highest escaper frequency. Hybridization to an $r p 49$ probe is a loading control. $(B)$ cDNA from RNA of adult males from each genotype was amplified by PCR ( 30 cycles). Primers from sequences retained in roX1 $1^{\text {ex } 6}$ were used for roX1 (261 bp) amplification. rps17 (210 bp) was amplified in the same tube as a positive control. No-RT controls produced no PCR products (data not shown). (C) Western analysis of ro $X^{-}$mutants. The total cell extract from one adult fly was loaded in each lane; $80 \mu \mathrm{g}$ of total SL- 2 cell extract was loaded as a positive control. The antibodies used for blotting are shown at left. The full genotype of the roX mutant is $y$ w roX1ex6 $D f(1) r o X 2^{52}\left[w^{+} 4 \Delta 4.3\right] ; m s l 2 \mathrm{cn} /+$, which showed the lowest escaper frequency. ro $X^{-}$mutants with different genetic backgrounds and escaper frequencies showed similar results (data not shown). A similar level of MSL3 was also detected with or without roX RNA (data not shown). A Western blot for $\alpha$-tubulin was a loading control.

cal spreading from roX loci operates in parallel with a second route where soluble MSL complexes diffuse and reattach to distant segments of the $\mathrm{X}$ chromosome. We can alter the proportion of MSL complexes entering each pathway by manipulating the amount of MSL proteins or roX RNAs present. We speculate that the underlying mechanism controlling these two outcomes rests on how efficiently MSL subunits can assemble into functional complexes (Fig. 1).

\section{Materials and methods}

Fly stocks and genetic crosses

Flies were raised on standard cornmeal-yeast-agar-molasses medium containing propionic acid. To obtain X-chromosome insertions of roX transgenes, [ $w^{+}$GMroX1-69C] and [ $w^{+}$GMroX2-40A] were remobilized in a roX $X^{-}$mutant background $\left\{y w\right.$ roX $1^{\text {ex6 }} D f(1)$ roX $2^{52}\left[w^{+} 4 \Delta 4.3\right]$; Park et al. 2002\} using genomic $P$ transposase (Robertson et al. 1988). The new transgenic insertion sites were mapped by inverse PCR and sequencing. To overexpress MSL1 and MSL2, y $w$ (wild type), y w roX1ex6 (Kelley et al. 1999), $w$ Df(1)roX2 ${ }^{52}$; [ $\left.w^{+} 4 \Delta 4.3\right]$ (Meller and Rattner 2002), y w roX $1^{\text {ex6 }} D f(1) r o X 2^{52}\left[\right.$ GMroX1-13A] [ $\left.w^{+} 4 \Delta 4.3\right]$ or y $w$ roX $1^{\text {ex6 }} D f(1)$ roX $2^{52}$ [GMroX2-14F] [ $\left.\mathrm{w}^{+} 4 \Delta 4.3\right]$ females were crossed with $\mathrm{w} / \mathrm{Y} ; \mathrm{msl2}, \mathrm{cn} /+$; [ $\mathrm{w}^{+}$ H83M1][ $w^{+}$H83M2]/TM6B, Tb males, and non- $T b$ male third-instar larvae were collected for anti-MSL1 immunostaining of polytene chromosomes. For Northern and Western blots, $y w$ (wild type), $y w \operatorname{roX} 1^{e x 6}, w$ $D f(1) r o X 2^{52}$; [ $\left.w^{+} 4 \Delta 4.3\right]$ or yw roX $1^{\text {ex6 }} D f(1) r o X 2^{52}\left[w^{+} 4 \Delta 4.3\right]$ females were crossed with $w / Y$; msl2 $\mathrm{cn} ;\left[w^{+}\right.$H83M1] $\left[w^{+}\right.$H83M2] $/+$males. The 
resulting adult male progeny carrying the MSL1 and MSL2 transgenes were selected by eye color. [ $\left.\mathrm{W}^{+} 4 \Delta 4.3\right]$ supplies essential genes lost in $D f(1) r o X 2^{52}$ (Meller and Rattner 2002).

Immunostaining, Northern, and Western analyses

Immunostaining of polytene chromosomes, Northerns, and Westerns were as described previously (Kelley et al. 1999).

\section{$R T-P C R$}

Five micrograms of total RNA from adult males was reverse-transcribed using SuperScriptII reverse transcriptase (Invitrogen) and oligo(dT) primers, as described previously (Meller et al. 2000). Ten percent $(2 \mu \mathrm{L})$ of the $\mathrm{RT}$ reaction was used in a 50- $\mu \mathrm{L}$ PCR amplification by using $0.2 \mu \mathrm{M}$ rps17 primers (F: 5'-CGAACCAAGACGGTGAAGAAG-3' and R: 5'-CC TGCAACTTGATGGAGATACC-3') and roX1 primers (5A: $5^{\prime}$-CCCAGA AGAAACTGCCACTGC-3' and 7 $\mathrm{B}^{\prime}$ : 5'-AATGTCCCTTTTCGAGCG$\left.3^{\prime}\right)$. PCR was performed as follows: at $94^{\circ} \mathrm{C}$ for 4 min, 30 cycles (at $94^{\circ} \mathrm{C}$ for $30 \mathrm{sec}$, at $55^{\circ} \mathrm{C}$ for $30 \mathrm{sec}$, at $72^{\circ} \mathrm{C}$ for $\left.1 \mathrm{~min}\right)$, and at $72^{\circ} \mathrm{C}$ for $10 \mathrm{~min}$. RT-PCR products were electrophoresed and stained with EtBr.

Immunoprecipitation and subtractive hybridization of RNA from MSL complexes

Total protein extracts of wild-type embryos (0 24 h old) were prepared by homogenization and sonication as described previously (Smith et al. 2000) in extract buffer [20 mM HEPES at pH 7.6, $70 \mathrm{mM} \mathrm{KCl,} 2 \mathrm{mM} \mathrm{DTT}$,

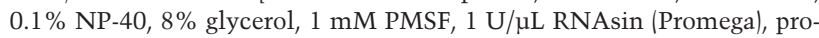
tease inhibitor cocktail; Lanz et al. 1999]. Extracts containing $10 \mathrm{mg}$ of total protein were incubated with $10 \mu \mathrm{L}$ of rabbit polyclonal $\alpha$-MLE antibody, and the RNA from that immunoprecipitate was isolated as described previously (Meller et al. 2000). This RNA was used to make tester cDNA, whereas $10 \mu \mathrm{g}$ of total RNA from adult female flies was used to make driver cDNA for subtraction (Clontech PCR-select cDNA subtraction kit). The resulting MSL-complex-specific cDNA fragments that survived the subtraction were amplified and subcloned for sequencing.

\section{Acknowledgments}

We are grateful to R.L. Kelley for help with Figure 1, for critical reading of the manuscript, and for many helpful discussions. We thank A. Alekseyenko, X. Bai, and C. Stuckenholz for critical reading of the manuscript and C. Stuckenholz for fly stocks and sharing unpublished data. We thank H. Kennedy and R. Richman for excellent technical support. This work was supported by the Welch Foundation (Q-1359), the National Institutes of Health (GM45744), and the Howard Hughes Medical Institute. M.I.K. is an HHMI Investigator.

The publication costs of this article were defrayed in part by payment of page charges. This article must therefore be hereby marked "advertisement" in accordance with 18 USC section 1734 solely to indicate this fact.

\section{References}

Amrein, H. and Axel, R. 1997. Genes expressed in neurons of adult male Drosophila. Cell 88: 459-469.

Badenhorst, P., Voas, M., Rebay, I., and Wu, C. 2002. Biological function of the ISWI chromatin remodeling complex NURF. Genes \& Dev. 16: 3186-3198.

Bannister, A.J., Zegerman, P., Partridge, J.F., Miska, E.A., Thomas, J.O., Allshire, R.C., and Kouzarides, T. 2001. Selective recognition of methylated lysine 9 on histone $\mathrm{H} 3$ by the HP1 chromo domain. Nature 410: 120-124.

Belote, J.M. and Lucchesi, J.C. 1980. Control of X chromosome transcription by the maleless gene in Drosophila. Nature 285: 573-575.

Chang, K.A. and Kuroda, M.I. 1998. Modulation of MSL1 abundance in female Drosophila contributes to the sex specificity of dosage compensation. Genetics 150: 699-709.

Copps, K., Richman, R., Lyman, L.M., Chang, K.A., RampersadAmmons, J., and Kuroda, M.I. 1998. Complex formation by the Drosophila MSL proteins: Role of the MSL2 RING finger in protein complex assembly. EMBO J. 17: 5409-5417.

Deuring, R., Fanti, L., Armstrong, J.A., Sarte, M., Papoulas, O., Prestel, M., Daubresse, G., Verardo, M., Moseley, S.L., Berloco, M., et al. 2000. The ISWI chromatin-remodeling pro- tein is required for gene expression and the maintenance of higher order chromatin structure in vivo. Mol. Cell 5: 355-365.

Dobzhansky, T. 1957. The X-chromosome in the larval salivary glands of hybrids Drosophila insularis and Drosophila tropicalis. Chromosoma 8: 691-698.

Franke, A. and Baker, B.S. 1999. The roX1 and roX2 RNAs are essential components of the compensasome, which mediates dosage compensation in Drosophila. Mol. Cell 4: 117-122.

Ho, Y., Elefant, F., Cooke, N., and Liebhaber, S. 2002. A defined locus control region determinant links chromatin domain acetylation with long-range gene activation. Mol. Cell 9: 291-302.

Kelley, R.L., Wang, J., Bell, L., and Kuroda, M.I. 1997. Sex lethal controls dosage compensation in Drosophila by a non-splicing mechanism. Nature 387: 195-199.

Kelley, R.L., Meller, V.H., Gordadze, P.R., Roman, G., Davis, R.L., and Kuroda, M.I. 1999. Epigenetic spreading of the Drosophila dosage compensation complex from roX RNA genes into flanking chromatin. Cell 98: 513-522.

Lachner, M., O'Carroll, D., Rea, S., Mechtler, K., and Jenuwein, T. 2001. Methylation of histone H3 lysine 9 creates a binding site for HP1 proteins. Nature 410: 116-120.

Lanz, R.B., McKenna, N.J., Onate, S.A., Albrecht, U., Wong, J., Tsai, S.Y., Tsai, M.-J., and O'Malley, B.W. 1999. A steroid receptor coactivator, SRA, functions as an RNA and is present in an SRC-1 complex. Cell 97: 17-27.

Lee, J.T. and Jaenisch, R. 1997. Long-range cis effects of ectopic $\mathrm{X}$-inactivation centres on a mouse autosome. Nature 386: $275-279$.

Meller, V.H. and Rattner, B.P. 2002. The roX RNAs encode redundant male-specific lethal transcripts required for targeting of the MSL complex. EMBO J. 21: 1084-1091.

Meller, V.H., Wu, K.H., Roman, G., Kuroda, M.I., and Davis, R.L. 1997. roX1 RNA paints the X chromosome of male Drosophila and is regulated by the dosage compensation system. Cell 88: 445-457.

Meller, V.H., Gordadze, P.R., Park, Y., Chu, X., Stuckenholz, C., Kelley, R.L., and Kuroda, M.I. 2000. Ordered assembly of roX RNAs into MSL complexes on the dosage compensated X chromosome in Drosophila. Curr. Biol. 10: 136-143.

Nakayama, J., Rice, J.C., Strahl, B.D., Allis, D.C., and Grewal, S.I. 2001. Role of histone H3 lysine 9 methylation in epigenetic control of heterochromatin assembly. Science 292: 110-113.

Offermann, C.A. 1936. Branched chromosomes as symmetrical duplications. J. Genet. 32: 103-116.

Palmer, M.J., Richman, R., Richter, L., and Kuroda, M.I. 1994. Sex-specific regulation of the male-specific lethal-1 dosage compensation gene in Drosophila. Genes \& Dev. 8: 698-706.

Park, Y., Kelley, R.L., Oh, H., Kuroda, M.I., and Meller, V.H. 2002. Extent of chromatin spreading determined by roX RNA recruitment of MSL proteins. Science 298: 1620-1623.

Richter, L., Bone, J.R., and Kuroda, M.I. 1996. RNA-dependent association of the Drosophila maleless protein with the male X chromosome. Genes Cells 1: 325-336.

Robertson, A.M., Preston, C.R., Phillis, R.W., Johnson-Schlitz, D., Benz, W.K., and Engels, W.R. 1988. A stable genomic source of $P$ element transposase in Drosophila melanogaster. Genetics 118: 461-470.

Smith, E.R., Pannuti, A., Gu, W., Steurnagel, A., Cook, R.G., Allis, C.D., and Lucchesi, J.C. 2000. The Drosophila MSL complex acetylates histone $\mathrm{H} 4$ at lysine 16, a chromatin modification linked to dosage compensation. Mol. Cell. Biol. 20: 312-318.

Stuckenholz, C. 2002. "Functional redundancy within roX1, a noncoding RNA involved in dosage compensation in Drosophila melanogaster." Ph.D. thesis, Baylor College of Medicine, Houston, TX. 


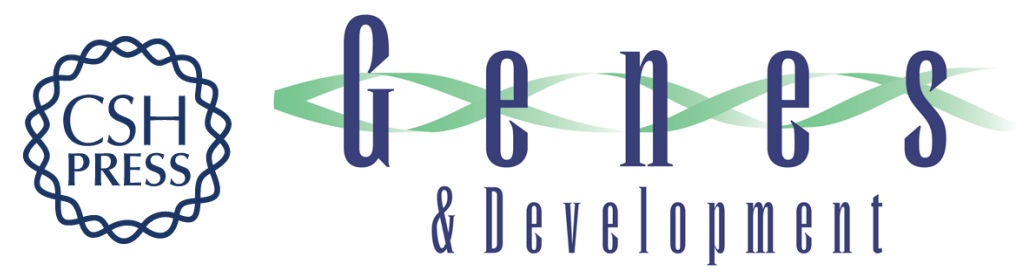

\section{Local spreading of MSL complexes from roX genes on the Drosophila $\mathrm{X}$ chromosome}

Hyangyee Oh, Yongkyu Park and Mitzi I. Kuroda

Genes Dev. 2003, 17:

Access the most recent version at doi:10.1101/gad.1082003

Supplemental http://genesdev.cshlp.org/content/suppl/2003/06/09/17.11.1334.DC1
Material

References This article cites 24 articles, 9 of which can be accessed free at:

http://genesdev.cshlp.org/content/17/11/1334.full.html\#ref-list-1

License

Email Alerting

Receive free email alerts when new articles cite this article - sign up in the box at the top

Service

right corner of the article or click here.

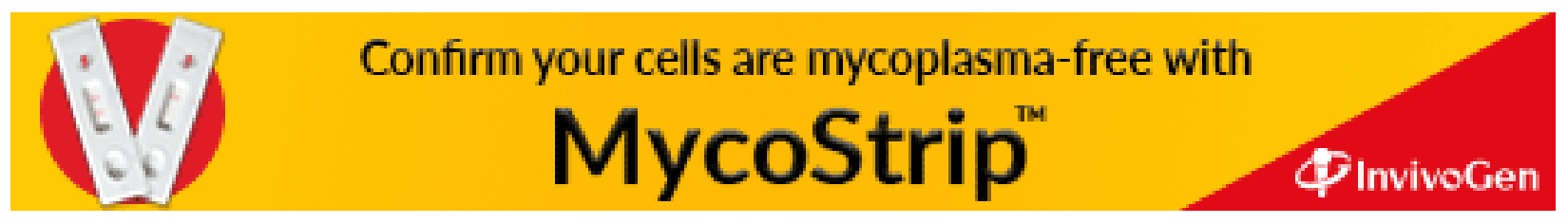

